\title{
Article \\ Effect of Graphene Nanoplatelet on the Carbonation Depth of Concrete under Changing Climate Conditions
}

\author{
Yingzi Zhang ${ }^{1}{ }^{\circledR}$, Yanze Wang ${ }^{1}$, Mingqian Yang ${ }^{1}$, Huatao Wang ${ }^{2}$, Guofang Chen ${ }^{1, *}$ and Song Zheng ${ }^{1}$ \\ 1 Department of Civil Engineering, Harbin Institute of Technology, Weihai 264209, China; \\ zhyz@hit.edu.cn (Y.Z.); E0816438@u.nus.edu (Y.W.); E0682725@u.nus.edu (M.Y.); \\ zhengsong@sdws.edu.cn (S.Z.) \\ 2 School of Materials Science and Engineering, Harbin Institute of Technology, Weihai 264209, China; \\ wanghuatao@hit.edu.cn \\ * Correspondence: gfch@hit.edu.cn; Tel.: +86-134-0631-1568
}

check for

updates

Citation: Zhang, Y.; Wang, Y.; Yang, M.; Wang, H.; Chen, G.; Zheng, S. Effect of Graphene

Nanoplatelet on the Carbonation Depth of Concrete under Changing Climate Conditions. Appl. Sci. 2021 11, 9265. https://doi.org/10.3390/ app11199265

Academic Editors: Petr Korusenko and Sergey Nesov

Received: 7 September 2021

Accepted: 3 October 2021

Published: 6 October 2021

Publisher's Note: MDPI stays neutral with regard to jurisdictional claims in published maps and institutional affiliations.

Copyright: (c) 2021 by the authors. Licensee MDPI, Basel, Switzerland. This article is an open access article distributed under the terms and conditions of the Creative Commons Attribution (CC BY) license (https:// creativecommons.org/licenses/by/ $4.0 /)$.

\begin{abstract}
Climate change has been unprecedented in the past decades or even thousands of years, which has had an adverse impact on the mechanical properties of concrete structures. Many researchers have begun to study new concrete materials. Graphene nanoplatelet (GNP) is an attractive nanomaterial that can change the crystal structure of concrete and improve durability. The aim of the present study was to investigate the effect of GNP $(0.05 \% \mathrm{wt})$ on the carbonation depth of concrete under simulated changing climate conditions (varying temperature, relative humidity, and carbon dioxide $\left(\mathrm{CO}_{2}\right)$ concentration), and compare it with ordinary concrete. When the concentration of $\mathrm{CO}_{2}$ is variable, the carbonation depth of graphene concrete is $10 \%$ to $20 \%$ lower than that of ordinary concrete. When the temperature is lower than $33^{\circ} \mathrm{C}$, the carbonation depth of graphene concrete is less than that of the control sample; however, above $33^{\circ} \mathrm{C}$, the thermal conductivity of GNP increases the carbonation reaction rate of concrete. When the humidity is a variable, the carbonation depth of graphene concrete is less than $15 \%$ to $30 \%$ of ordinary concrete, and when the humidity is higher than $78 \%$, the difference in the carbonation depth between the ordinary concrete and the graphene concrete decreases gradually. The overall results indicated that GNP has a favorable effect on anti-carbonation performance under changing climate conditions.
\end{abstract}

Keywords: climate change; concrete; graphene nanoplatelet (GNP); carbonation depth

\section{Introduction}

Reinforced concrete (RC) structures are widely used in various fields, such as civil engineering, water conservancy, and bridges. Concrete is an alkaline composite material. The diffusion of carbon dioxide of the atmospheric environment in concrete dry secretions and its reaction in not saturated voids results in a decrease in the alkalinity near the reinforced bars. Then, corrosion happens when the passive film on the surface of the steel bar is damaged. Unlike other corrosion processes of RC, such as chloride attack, acid rain corrosion, sulfate attack, freeze-thawing damage, etc., that occur in specific areas or environmental conditions, carbonation reaction happens anywhere in the natural state [1]. Previous studies have shown that carbonation of concrete and associated corrosion of the embedded reinforcement is harmful to the social safety and service life of RC structures [2-8]. Carbonation reaction is influenced by the service environment, especially carbon dioxide $\left(\mathrm{CO}_{2}\right)$ concentration, temperature, and relative humidity $(\mathrm{RH})[9,10]$. Meanwhile, current global industrialization is developing rapidly, and the emission of large amounts of greenhouse gases has caused the global $\mathrm{CO}_{2}$ concentration to rise continuously. The fifth assessment report of the Intergovernmental Panel on Climate Change (IPCC) reports that the present global climate change is the most serious from earliest times to the present day, and between 1901 and 2010, the global mean sea level rose by 0.19 [0.17 to 0.21 ] m [11]. The World Meteorological Organization [12] reported that the $\mathrm{CO}_{2}$ concentration 
in the global atmosphere reached the maximum value of the last 800,000 years in 2016 . The sudden changes of climate change are without precedents in history. McMichael reported that the global average temperature has increased by $0.5^{\circ} \mathrm{C}$ in the past 40 years and is supposed to rise by more than $1.4-5.8^{\circ} \mathrm{C}$ by the end of this century [13]. Global climate change worsens the work environment of RC structures. Therefore, it can accelerate the corrosion process of RC structures. In recent years, concern about climate change has been at the core of some countries' policies. Yoon [9] discussed the influences of climate change on the carbonation progress of concrete, and put forward a revised model to assess the carbon dioxide diffusion coefficient of concrete. Nonetheless, the equation disregards the influence of temperature and relative humidity on concrete carbonation. Stewart et al. used advanced probabilistic and reliability-based theory to study concrete carbonation because of climate change $\left(\mathrm{CO}_{2}\right.$ concentration, temperature, and relative humidity) in Australia [14,15]. After, they researched the time-dependent reliability to evaluate damage to RC structures in China, and concluded that climate change was the important factor for these infrastructures [16]. In view of the forecast data of climate by the IPCC and observation files of different climate regions in China, Guofang et al. proposed a modified model considering $\mathrm{CO}_{2}$ concentration, temperature, and relative humidity, and reported that the current climate change will accelerate the carbonation process [17].

In recent years, many researchers have begun to study the usage of many new concrete materials, especially nanomaterials, such as nano-kaolinite clay [18,19], nano-MgO [20], nano-silica [21,22], nano alumina [23], and graphene nanomaterials [24-26]. These experiments showed that nanomaterials have favorable effects on the mechanical properties of cementitious materials. Graphene as a new star of nano materials can be added into cementitious materials to improve their physical and mechanical properties because of graphene's extraordinary performance. Through the mechanical test of the cement paste mixed with $0.05 \mathrm{wt} \%$ graphene oxide (GO), Pan et al. found that GO can enhance the compressive and flexural strength [27]. Wang et al. discovered that GO could accelerate the hydration process of cement and improve the tightness of cement paste [28]. Graphene nanoplatelets (GNPs) have also been added into concrete. Du studied the durability of graphene-modified concrete, and researched the transport properties of graphene concrete in a chloride environment. They found that graphene could increase the transport resistance of concrete, whereas they thought that GNP could not improve the compressive strength of concrete [29]. However, Guofang et al. discovered that GNP could enhance the compressive properties of concrete within the appropriate range, and GNP had a positive effect on the freeze-thaw resistance of concrete [30]. So far, less research has been conducted on the mechanical property of graphene-modified concrete. Consequently, the durability of graphene-modified concrete is a topic that is attracting interest from a great number of researchers worldwide.

The purpose of the paper was to investigate the influences of GNP on the carbonation of concrete in the context of the changing climate, using the rapid corrosion method. The carbonation depth was measured on concrete samples with and without GNP that were subjected to three simulating climate-changing environments. Moreover, scanning electron microscopy (SEM) was used to observe the effect of GNP on the micro-structure of concrete.

\section{Experimental Program}

\subsection{Material}

Ordinary Portland cement of grade 42.5 was used to make the mortar mix. The main chemical properties are shown in Table 1 . The maximum sizes of natural sand and coarse aggregate were 5 and $20 \mathrm{~mm}$, respectively, and the water used was tap water. The sample GNP used was the same product as that used in the literature [30]. Moreover, $\mathrm{CO}_{2}$ gas with a purity of $99.99 \%$ was purchased from Weihai Xinyue Chemical and Glass Co. Ltd. in China. According to the preliminary test results of the research group [30], graphene concrete has a higher compressive strength and durability when the graphene content 
accounts for $0.05 \%$ of the cement mass. Therefore, GC 0.05 was taken as the studied dosage for the graphene concrete in this test. The graphene concrete mix is shown in Table 2.

Table 1. The main chemical properties of cement.

\begin{tabular}{lccccccc}
\hline Composition & $\mathrm{SiO}_{2}$ & $\mathrm{SO}_{3}$ & $\mathrm{MgO}$ & $\mathrm{Al}_{2} \mathrm{O}_{3}$ & $\mathrm{Fe}_{2} \mathrm{O}_{3}$ & $\mathrm{CaO}$ & Loss \\
\hline $\begin{array}{c}\text { Percentage } \\
(\%)\end{array}$ & 22.6 & 2.29 & 1.70 & 4.62 & 3.26 & 63.79 & 3.14 \\
\hline
\end{tabular}

Table 2. Graphene concrete mix proportion design.

\begin{tabular}{cccccc}
\hline Cement $/ \mathbf{k g}$ & Sand $/ \mathbf{k g}$ & Coarse Aggregate/kg & Water/kg & Sand Rate/\% & GNP/g \\
\hline 14.364 & 29.61 & 48.258 & 8.61 & 38 & 1.239 \\
\hline
\end{tabular}

\subsection{Specimen Preparation}

Two mixes of cement composites, which have a water to cement ratio (w/c) of 0.6 , were prepared. One mix was blended with $0.05 \% \mathrm{GNP}$ by the weight of cement. Another was a plain cement mix that serves as the control sample. According to the Chinese standard (GB/T50080-2016) [31], graphene suspension was dissolved in water and mixed well. Then, cement and graphene-water were poured into the mixer to blend for $20 \mathrm{~s}$. Next, all coarse aggregates were mixed for about $20 \mathrm{~s}$. Afterwards, all the sand was mixed for $20 \mathrm{~s}$, and finally, all the ingredients were blended together to obtain a homogenized mixture. After being blended well, concrete was poured into some cubic molds (size length is $100 \mathrm{~mm}$ ) and then compacted on a vibration table, with each group consisting of 3 samples. According to the test design, the required number of test samples is shown in Table 3. In total, 114 cubic samples were cured in laboratory conditions (temperature was about 20 degrees centigrade, relative humidity was $60 \%$ ). After $24 \mathrm{~h}$, all specimens were demolded and placed into a concrete standard curing room at a temperature of $20 \pm 2$ degrees centigrade and a relative humidity of $95 \pm 2 \%$ for 28 days in accordance with GB/T 50081 (Chinese standard 2002).

Table 3. Experimental group.

\begin{tabular}{|c|c|c|c|c|c|c|c|c|}
\hline \multicolumn{9}{|c|}{ Number of Concrete Specimens } \\
\hline Group & Concrete & 0 Day & 7 Days & 14 Days & 21 Days & 28 Days & 35 Days & 42 Days \\
\hline \multirow{2}{*}{$\mathrm{CO}_{2}$} & GC0 & 3 & 3 & 3 & 3 & 3 & 3 & 3 \\
\hline & GC0.05 & 3 & 3 & 3 & 3 & 3 & 3 & 3 \\
\hline \multirow{2}{*}{ Humidity } & GC0 & 3 & 3 & 3 & 3 & 3 & 3 & 0 \\
\hline & GC0.05 & 3 & 3 & 3 & 3 & 3 & 3 & 0 \\
\hline \multirow{2}{*}{ Temperature } & GC0 & 3 & 3 & 3 & 3 & 3 & 3 & 0 \\
\hline & GC0.05 & 3 & 3 & 3 & 3 & 3 & 3 & 0 \\
\hline Sum & & 18 & 18 & 18 & 18 & 18 & 18 & 6 \\
\hline
\end{tabular}

\subsection{Methods}

After the 28-day curing period, specimens were taken out. Three graphene concrete (GC0.05) samples and three corresponding samples (GC0) were used to measure the 28-day compressive strength. Other samples were placed in a drying oven at $60^{\circ} \mathrm{C}$ for $48 \mathrm{~h}$ according to the Chinese standard [32], and cooled down to room temperature. Then, the specimens were placed in a standard carbonation chamber made by Hebei Xinxin Instrument Co. Ltd. in China. The chamber could electronically control the carbon dioxide concentration, temperature, and relative humidity. The accelerated carbonation test of concrete was performed in three changing simulation environments. Three environments were selected to evaluate the effect of GNP mixed in concrete for each different atmospheric variable $\left(\mathrm{CO}_{2}\right.$ concentration, temperature, and relative humidity) on the carbonation process, with each environment running for 7-day intervals. After being corroded for 
different exposure periods, two groups of samples (three graphene concrete specimens and three corresponding specimens) were picked out, and then carbonation depth and scanning electron microscopy experiments were performed.

\subsubsection{Variable $\mathrm{CO}_{2}$ Concentration}

Concrete carbonation is a chemical process by which atmospheric $\mathrm{CO}_{2}$ reacts with $\mathrm{Ca}(\mathrm{OH})_{2}$ to form $\mathrm{CaCO}_{3}$. According to Fick's diffusion law, we know that when the outside $\mathrm{CO}_{2}$ concentration is higher, the difference between the inside and outside of the concrete is greater. The movement of molecules from the high-concentration ground to the low-concentration ground accelerates the rate of carbonation. Here, the temperature and humidity remained unchanged, and different $\mathrm{CO}_{2}$ concentrations were used to simulate the effect of different climate changes on the carbonation depth of concrete. According to the Chinese standard GB/T 50082-2009 [32], the curing environment of concrete carbonation is: $\mathrm{CO}_{2}$ concentration is $20 \pm 3 \%$, temperature is $20 \pm 5^{\circ} \mathrm{C}$, and humidity is $70 \pm 5 \%$. In order to decrease the difference in the $\mathrm{CO}_{2}$ concentration between the accelerated experiment and the natural state, the test environment was set as follows: $\mathrm{CO}_{2}$ concentration was $6 \sim 10 \%$, temperature was $25^{\circ} \mathrm{C}$, and relative humidity was $65 \%$. According to Talukdar.S [33], the formula of the $\mathrm{CO}_{2}$ concentration changing with time is as follows:

$$
C(t)=6+(4 / 42) t
$$

where $C(t)$ is the $\mathrm{CO}_{2}$ concentration (\%) and $t$ is the carbonation time (days).

By measuring the carbonation depth of GC0 and GC0.05 at 7, 14, 21, 28, 35, and 42 days, the influence of the $\mathrm{CO}_{2}$ concentration change on the concrete carbonation depth was speculated.

\subsubsection{Variable Temperature}

The carbonation reaction is an exothermic reaction, and an increase in temperature will accelerate the diffusion rate of $\mathrm{CO}_{2}$ and enhance the speed of movement between ions.

For general chemical reactions, the reaction rate increases by $2-3$ times for every $10{ }^{\circ} \mathrm{C}$ increase in temperature. In the carbonation reaction of concrete, researchers from various countries have different opinions on the influence of temperature on concrete carbonation. Some researchers think that the carbonation reaction is not sensitive to temperature change at a certain humidity because carbon dioxide diffusion is affected by humidity; some researchers believe that when the temperature is between 20 and $40{ }^{\circ} \mathrm{C}$, the influence of temperature on the carbonation rate is not obvious. Some studies have also shown that when the relative humidity is $75 \%$ and the temperature is increased from 20 to $40{ }^{\circ} \mathrm{C}$, the carbonation reaction will be greatly intensified. To study the effect of GNP on temperature changes on the carbonation depth of concrete, the experimental setting temperature was $25-45{ }^{\circ} \mathrm{C}$, relative humidity was $65 \%$, and $\mathrm{CO}_{2}$ concentration was $6 \%$. According to the empirical formula of Talukdar.S [33], the relationship between the temperature and carbonation time is as follows:

$$
T(t)=25+(20 / 35) t
$$

where $T(t)$ is the experimental temperature $\left({ }^{\circ} \mathrm{C}\right)$ and $t$ is the carbonation time (days).

By measuring the carbonation depth of GC0 and GC0.05 at 7, 14, 21, 28, and 35 days, the impact of temperature change on the carbonation depth of concrete was studied.

\subsubsection{Variable Relative Humidity}

The relative humidity of the environment is very important for the carbonation reaction of concrete because it will affect the content of concrete pore water. $\mathrm{CO}_{2}$ diffusion dominates the carbonation progress, and the reaction will slow down when the relative humidity becomes large. When the pores in concrete are saturated with water, carbon dioxide scarcely reacts with the concrete because $\mathrm{CO}_{2}$ hardly diffuses in water. Moreover, the carbonation reaction also becomes slow when the humidity is too low. $\mathrm{CO}_{2}$ cannot 
dissolve into the thin layer of water covering the pores even if $\mathrm{CO}_{2}$ diffuses into the capillary pores. Therefore, there is a suitable range of relative humidity for the carbonation reaction of concrete. Yuan Y [34] found that the optimal range for carbonation is $50-70 \%$. In this paper, keeping the temperature and $\mathrm{CO}_{2}$ concentration unchanged, and altering the humidity to simulate the effect of GNP in different climate changes on the carbonation depth of concrete. We set the experimental temperature at $25{ }^{\circ} \mathrm{C}$, the humidity was $50-85 \%$, and the $\mathrm{CO}_{2}$ concentration was $6 \%$. According to the formula of Talukdar.S [21], the relationship between humidity and carbonation time is as follows:

$$
R H(t)=50+(35 / 35) t
$$

where $R H(t)$ is the experimental humidity (\%) and $t$ is the carbonation time (days).

By measuring the carbonation depth of GC0 and GC0.05 at 7, 14, 21, 28, and 35 days, the influence of humidity change on the carbonation depth of concrete was investigated.

\subsubsection{Scanning Electron Microscopy}

To know the effects of graphene on the micro-performance of concrete in different simulated environments, specimens with dimensions of $4 \times 4 \times 4 \mathrm{~mm}$ were used for the micro structural morphology test, which was obtained from the plain concrete samples. To produce conductive samples, about 10-nm-thick gold was sprayed on the specimens surface before the SEM experiment. Afterwards, the SEM test was conducted using a Tescan Vega II SEM system in the Analysis and Testing Center. To compare the two types of concrete samples, the same procedure was carried out on the graphene concrete specimens.

\subsubsection{Carbonation Depth Measurement}

After the carbonation test for the required days, the samples were removed from the carbonization room. The samples were split by a BOSCH universal cutting machine at half the width, and each cross-section was sprayed with a mixture of $1 \%$ phenolphthalein and $70 \%$ ethyl alcohol. The carbonated part does not change color, and the uncarbonated part is alkaline and appears purple (Figure 1). The carbonation depth of each sample could be obtained by averaging the depth along the perimeter of the carbonation front. Three samples were taken as a group, and the average carbonation depth of each group is the arithmetic average value of the test results of three specimens as the measured value.

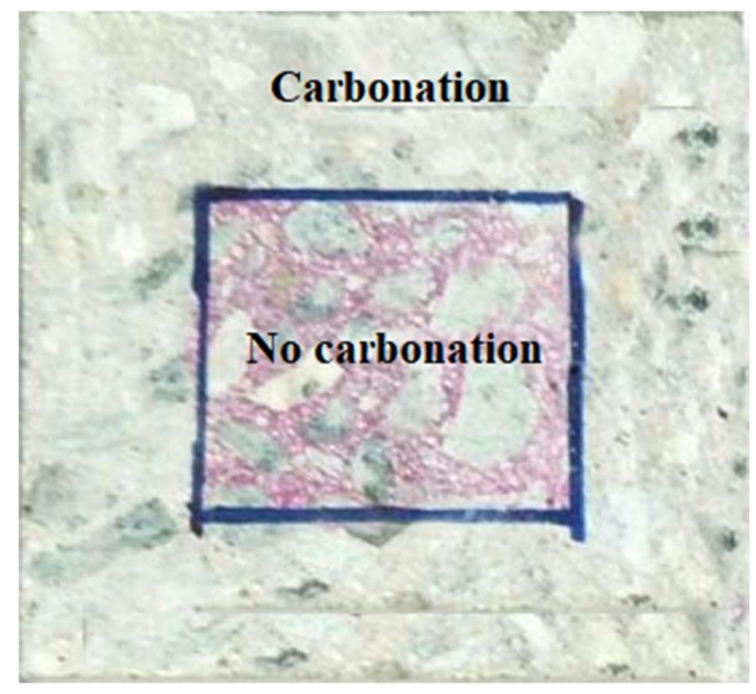

Figure 1. Carbonated concrete section. 


\section{Results and Discussion}

According to the Chinese standard [35] for mechanical properties of concrete, three samples were tested for each group of specimens. Additionally, the 28-day compressive test was performed before corroding at a loading rate of $0.5 \mathrm{MPa} / \mathrm{s}$ in this experiment.

\subsection{Variable $\mathrm{CO}_{2}$ Concentration}

In the experiment, the 28-day compressive strength of GC0 and GC0.05 was 31.2 and $37.6 \mathrm{MPa}$, respectively. GC0 and GC0.05 were subjected to a changing $\mathrm{CO}_{2}$ concentration scenario, ranging from $6 \%$ to $10 \%$, while the relative humidity and temperature were constant values of $65 \%$ and $25^{\circ} \mathrm{C}$, respectively.

\subsubsection{Scanning Electron Microscopy}

SEM observation experiments of when the $\mathrm{CO}_{2}$ concentration reached $8 \%$ and $10 \%$ (carbonation time was 21 and 42 days, respectively) were conducted to study the microstructure of two kinds of concrete before and after carbonation.

The microstructure of the reference sample is shown in Figure 2. From Figure 2a, it can be seen that there are many fibrous C-S-H gels in the inner structure of the no carbonation concrete, and the cementites are closely arranged and the pores are few and short. However, the square plate $\mathrm{Ca}(\mathrm{OH})_{2}$ crystals $(\mathrm{CH}$ crystals) and the needle rod ettringite Aft crystal overlap. When the $\mathrm{CO}_{2}$ concentration is $8 \%$, square-shaped $\mathrm{CH}$ crystals, needle rod ettringite Aft crystal, and C-S-H gels can still be observed as shown in Figure 2b. Compared with that in Figure 2a, the size of the C-S-H gel pores increased significantly, spherical $\mathrm{CaCO}_{3}$ is filled in the internal space of concrete, and its arrangement is disorderly and irregular, which indicates that carbon dioxide penetrated into the concrete and reacted with $\mathrm{Ca}(\mathrm{OH})_{2}$. Thus, the carbonation products improve the compactness of concrete. As shown in Figure 2c, when the $\mathrm{CO}_{2}$ concentration is $10 \%$, it can be found that the internal microstructure of the concrete is well filled, the overall surface of the structure is relatively flat, and there is no material with obvious shape, but there are large convex holes, and the holes wall is thin. Compared with that in Figure $2 \mathrm{~b}$, more $\mathrm{CaCO}_{3}$ is generated, which may be due to more carbon dioxide invading into the concrete. The carbonation reaction is more sufficient, which causes pore expansion of the concrete and makes the internal structure of concrete loosen, and even results in the interface of the paste and aggregate losing its bonding performance.

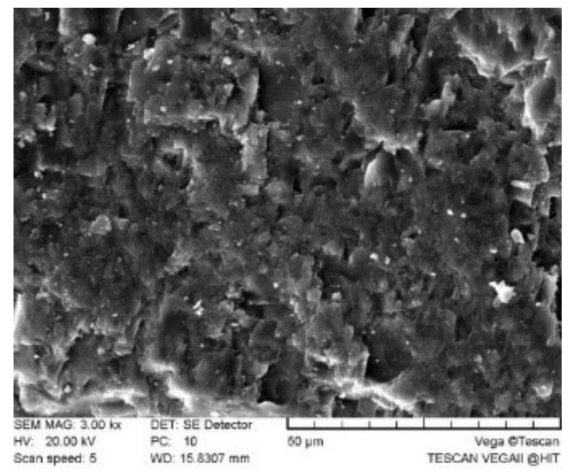

(a)

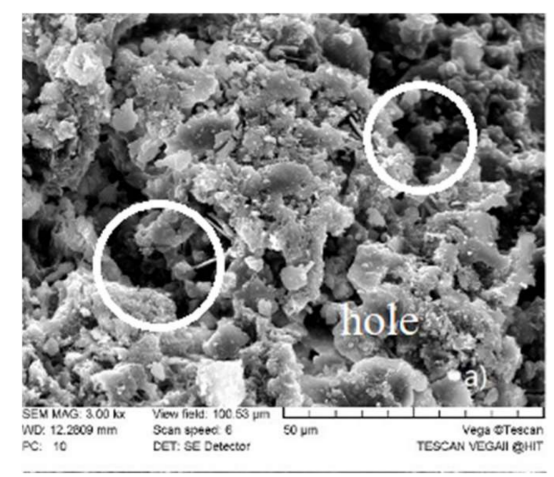

(b)

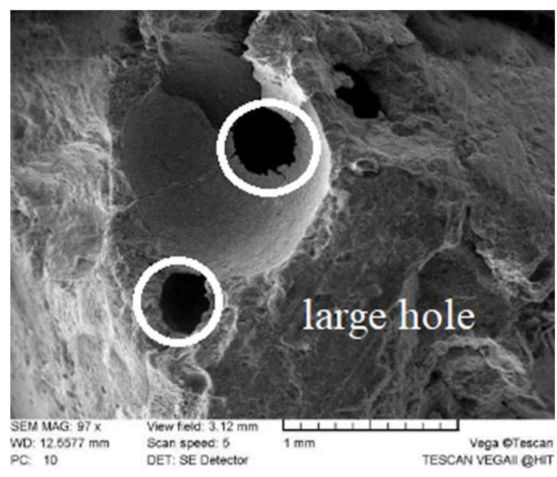

(c)

Figure 2. SEM images of the plain concrete in different $\mathrm{CO}_{2}$ concentrations. (a) No corrosion, (b) $8 \% \mathrm{CO}_{2}$ concentration, and (c) $10 \% \mathrm{CO}_{2}$ concentration.

According to the existing literature $[28,29,36]$, graphene can be filled in the voids of cement-based products; therefore, it can improve the hydration rate and degree of cement, and also change the size and shape of hydration products. However, it is considered that graphene does not participate in the hydration reaction of cement, so the type of cement products will not be changed. As can be seen from Figures 2a and 3a, compared with 
ordinary concrete, GNP was well-dispersed in the cement. The hydration products of graphene concrete have more calcium silicate gels arranged together, and few pores and $\mathrm{CaCO}_{3}$ crystals inside overlap with each other, and some layer-like hydrated structures were exhibited, which indicates that GNP makes the microstructure of concrete denser. From Figure 3b, it can be seen that when the $\mathrm{CO}_{2}$ concentration is $8 \%$ (carbonation time of 21 days), there are more square plate $\mathrm{CH}$ crystals and spherical $\mathrm{CaCO}_{3}$ in graphene concrete. However, compared with Figure 2a, the number of gel structures C-S-H obviously decreased. We also found that amorphous hydrated calcium silicate gel (C-S-H) is fibrous, and the cementitious materials are closely cross-linked. Furthermore, some holes and a few cracks are observed. Compared with Figure 2c, the inner part of the graphene concrete structure is denser, there are no large holes, and the pore structure is evenly distributed. This indicates that GNP could delay the carbonation process of concrete. The SEM graphs provide an explanation for the difference in the carbonation depth between the graphene concrete and the corresponding specimen.

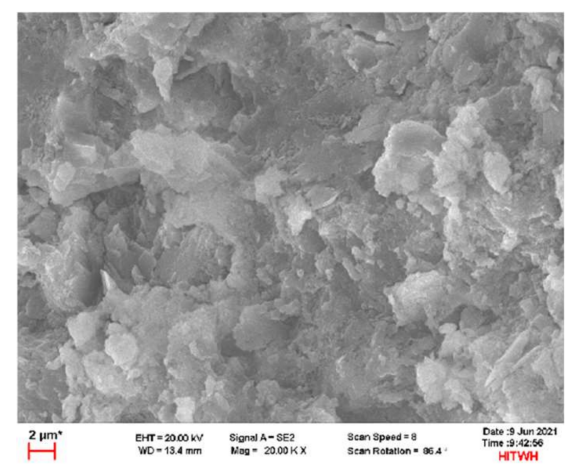

(a)

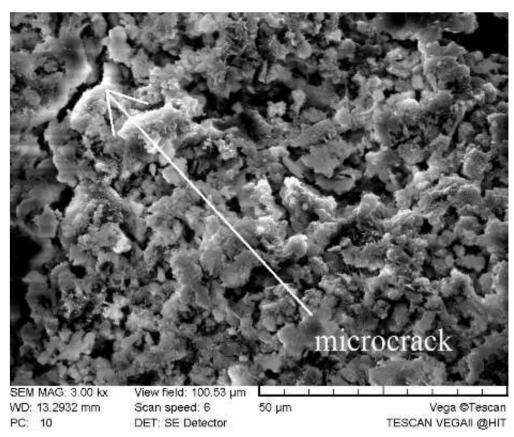

(b)

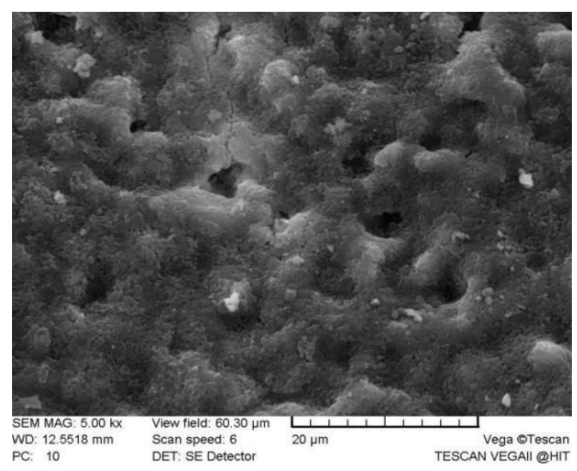

(c)

Figure 3. SEM images of the graphene concrete in different $\mathrm{CO}_{2}$ concentrations. (a) No corrosion, (b) $8 \% \mathrm{CO}_{2}$ concentration, and (c) $10 \% \mathrm{CO}_{2}$ concentration.

\subsubsection{Carbonation Depth}

The relationship between the carbonation depth of concrete and $\mathrm{CO}_{2}$ concentration is shown in Figure 4. It can be found that the carbonation depth of the two kinds of concrete is gradually increasing, but the carbonation depth of GC0.05 is generally $10 \%$ to $20 \%$ lower than that of GC0. Therefore, from these data, we can infer that the incorporation of GNP can slow down the carbonation process. The possible reasons are as follows: firstly, the impermeability of graphene makes it a barrier to prevent the diffusion of $\mathrm{CO}_{2}$; secondly, GNP can accelerate the hydration of cement and make the microstructure compact; and thirdly, the layered structure of graphene nanosheets can refine the pore structure of concrete. This makes GNP improve the carbonation resistance of concrete under certain conditions.

It was also found that when the $\mathrm{CO}_{2}$ concentration reaches $10 \%$ (carbonation time is 42 days), the carbonation depth of GC0 increases and the reaction rate is accelerated. It may be that the carbonation reaction causes the capillary water to evaporate, causing the surface tension inside the gel particles to increase. The concrete generates more cracks because of its compressed state, as shown in Figure $2 \mathrm{c}$ in the SEM experiment. The increasing $\mathrm{CO}_{2}$ concentration adds to the pressure of the air, and the gradient effects cause a pressure difference on the surface of the concrete. Further, the gas is more likely to penetrate into the concrete, which accelerates the carbonation reaction process. The carbonation reaction rate of graphene concrete is slower than that of ordinary concrete, and there are less micro cracks in graphene concrete (Figure 3b). 


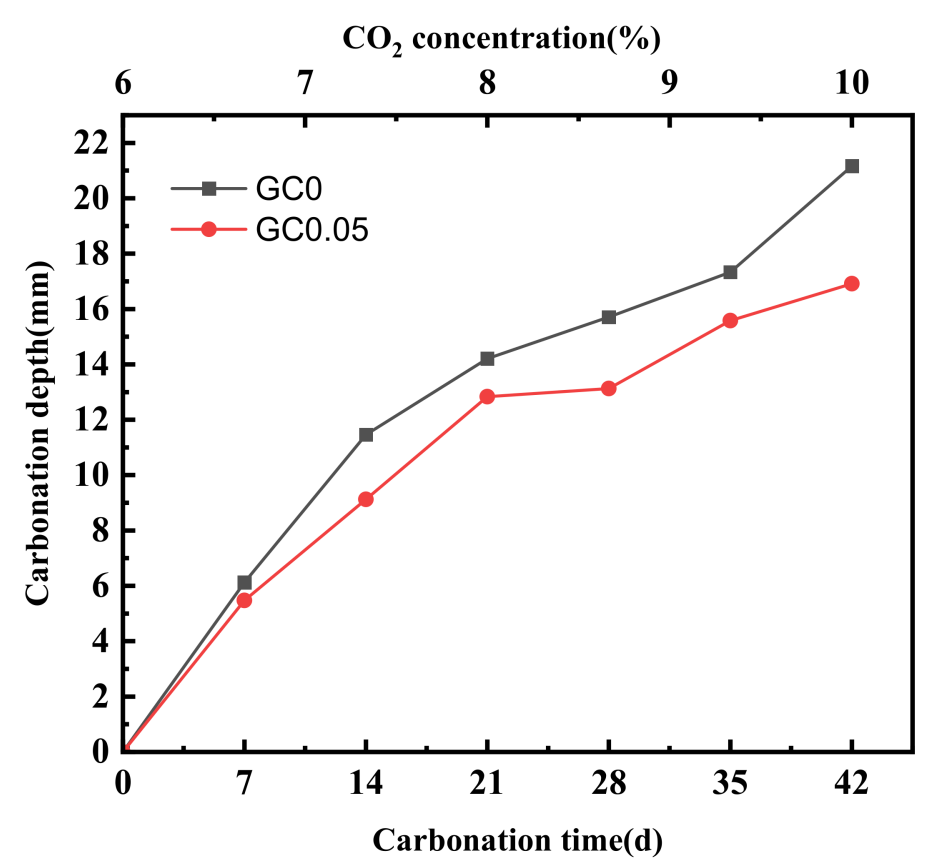

Figure 4. Relationship between concrete carbonation depth, time, and $\mathrm{CO}_{2}$ concentration.

\subsection{Variable Temperature}

Two groups of concrete specimens were subjected to changing temperature scenarios, ranging from 25 to $45^{\circ} \mathrm{C}$, while the $\mathrm{CO}_{2}$ concentration and relative humidity were $6 \%$ and $65 \%$, respectively. The 28-day compressive strengths of GC0 and GC0.05 were 32.5 and 38.3 $\mathrm{MPa}$, respectively.

\subsubsection{Scanning Electron Microscopy}

SEM observation experiments in which the temperature reached 29,37 , and $45{ }^{\circ} \mathrm{C}$ (carbonation time was 7, 21, and 35 days, respectively) were conducted to study the microstructure of two kinds of concrete before and after carbonation.

The microstructure of ordinary concrete is shown in Figure 5. When the temperature reaches $29^{\circ} \mathrm{C}$, from Figure $5 \mathrm{a}$, it can be seen that there are a lot of fibrous C-S-H gels that overlap with each other. Square plate $\mathrm{CH}$ crystals and a little calcium carbonate crystal can also be observed. We can see that the microstructure is relatively loose and there are many interconnected pores. When the temperature reaches $37^{\circ} \mathrm{C}$, compared with Figure 5a, small spherical calcium carbonate crystals, fibrous C-S-H crystals, and plate-shaped $\mathrm{CH}$ accumulated more compactly, filling the voids and improving the compactness of the microstructure. This means the carbonation reaction is accelerated. We can also see that the number of calcium carbonates in Figure $2 b$ is significantly higher than that in Figure $5 b$, and the number of $\mathrm{CH}$ crystals in Figure $5 b$ is lower than that in Figure $2 b$, which indicates that the influence of carbon dioxide on the carbonation degree of concrete is significantly greater than that of temperature under the same humidity and carbonation time (21 days). From Figure 5c, more spherical calcium carbonate crystals accumulate in the concrete, which reduces the internal voids and makes the structure denser. From Figure 5, with the extension of the temperature and carbonation time, it can be inferred that the calcium carbonate crystals generated gradually increased in this test. However, compared with Figure 2, there are not many cracks and holes in the concrete, which indicates that the influence of the carbon dioxide concentration is greater than that of the temperature rise on the carbonation resistance of ordinary concrete. 


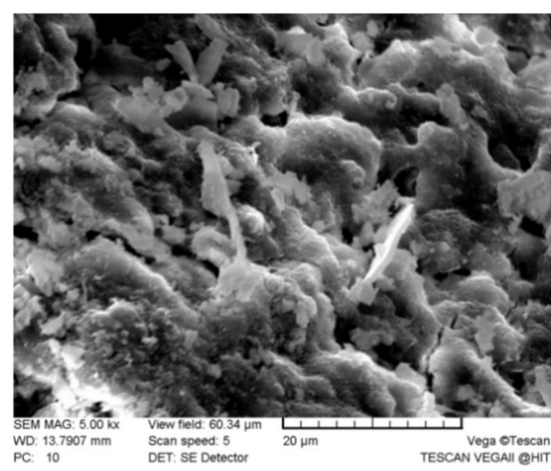

(a)

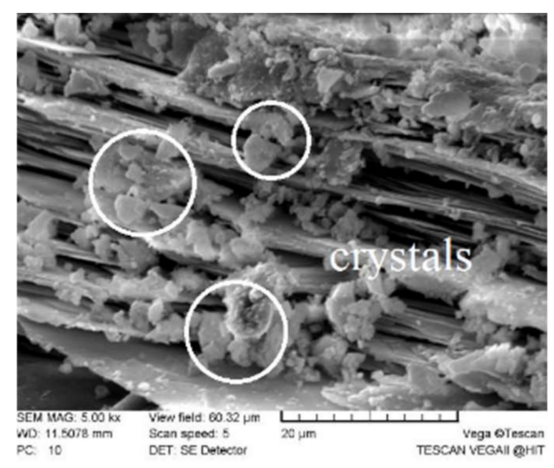

(b)

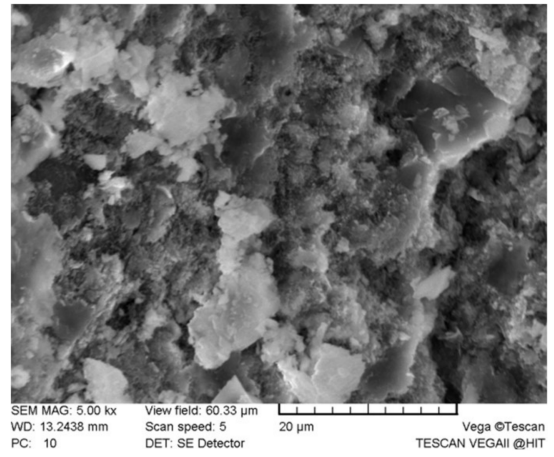

(c)

Figure 5. SEM images of plain concrete in different temperatures: (a) 29 , (b) 37 , and (c) $45^{\circ} \mathrm{C}$.

As shown in Figure 6a, when the temperature reaches $29^{\circ} \mathrm{C}$ (carbonation time is 7 days), it can be seen that the rod C-S-H gel and $\mathrm{CH}$ crystal are interconnected with each other, and a small amount of spherical $\mathrm{CaCO}_{3}$ crystal is formed. When the temperature reaches $37^{\circ} \mathrm{C}$, it can be observed that there are more spherical calcium carbonate crystals and AFt crystals and C-S-H gel generated in Figure $6 \mathrm{~b}$, and the pores are few and short. Hence, in this stage, the internal structure of GNP concrete becomes compact. With the increase of the temperature and carbonation time, it can be found that the spherical calcium carbonate increased obviously compared with Figure $6 \mathrm{~b}$. Moreover, there is an extended flower cluster structure, which extends one cluster after another and connects closely.

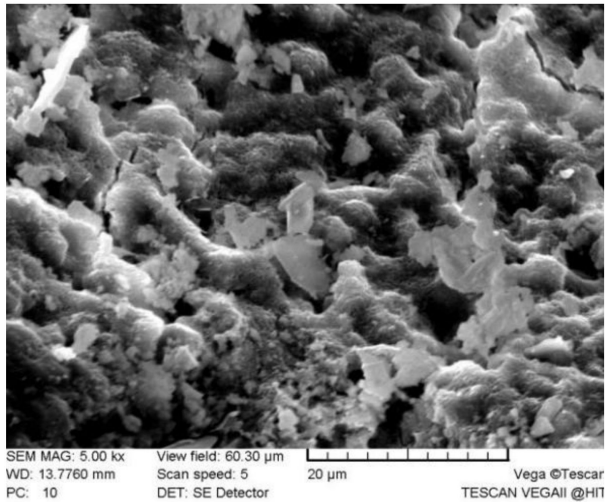

(a)

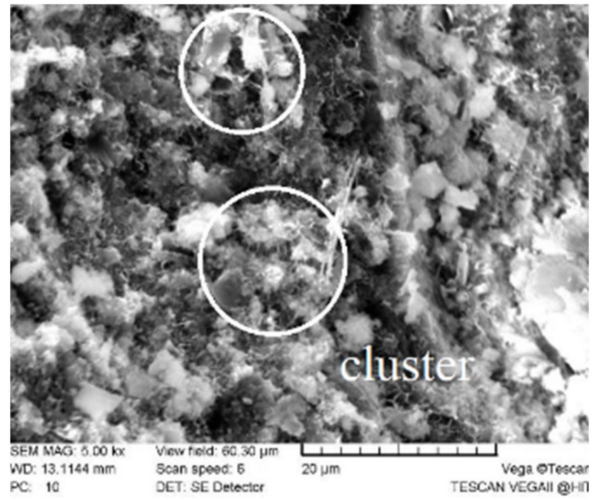

(b)

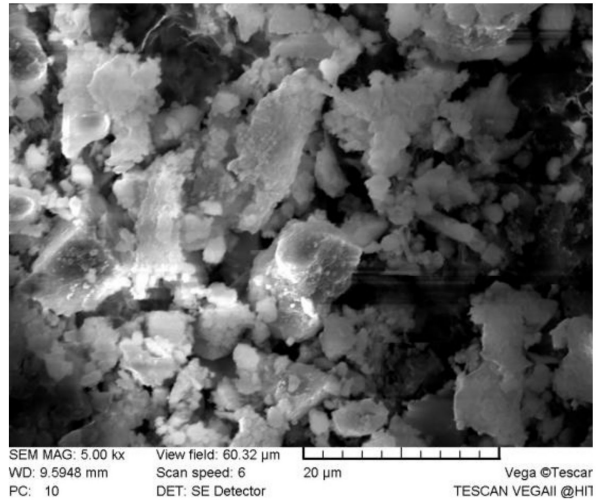

(c)

Figure 6. SEM images of graphene concrete in different temperatures: (a) 29, (b) 37, and (c) $45^{\circ} \mathrm{C}$.

Compared with Figures $5 a$ and $6 a$, there is little difference between them. There is more rod C-S-H gel and $\mathrm{CH}$ crystal dislocation from each other. From Figures $5 \mathrm{~b}$ and $6 \mathrm{~b}$, it can be seen that the amount of $\mathrm{CaCO}_{3}$ in graphene concrete is more than that of ordinary concrete. Comparison between Figures $5 \mathrm{c}$ and $6 \mathrm{c}$ shows that there are more spherical calcium carbonate crystals in graphene concrete, but it is not obvious in ordinary concrete, which means that the carbonation reaction of graphene concrete is more sufficient. Therefore, the increase in temperature may cause graphene to accelerate the carbonation reaction of concrete, which may be because graphene has good thermal conductivity. Therefore, the temperature sensitivity of graphene concrete is higher than that of ordinary concrete.

\subsubsection{Carbonation Depth}

The relationship between the carbonation depth of GC0 and GC0.05 with temperature is shown in Figure 7. 


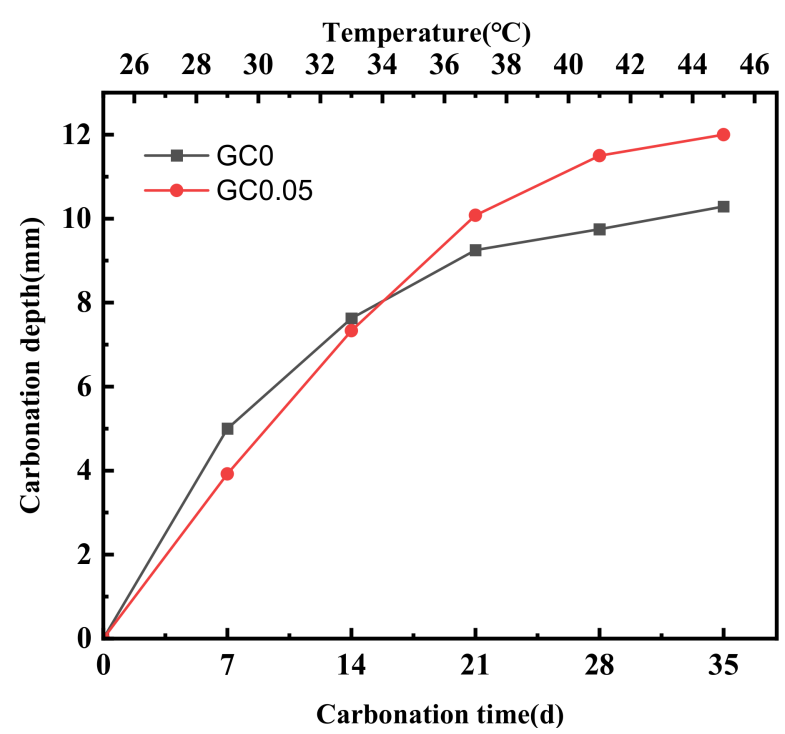

Figure 7. Relationship between concrete carbonation depth, time, and temperature.

Under the condition of climate change, the temperature increases with time. It can be seen that the carbonation depth of the two kinds of concrete increases gradually. This may be because the increase in temperature will accelerate the diffusion speed of $\mathrm{CO}_{2}$ and the movement speed of ions, and enhance the chemical reaction. Hence, it will accelerate the carbonation reaction. It is worth noting that the reaction rate first ascends and then grows slowly with the increase in temperature. At the initial stage of the test (the temperature is between 25 and $29^{\circ} \mathrm{C}$ ), the carbonation depth of graphene concrete is lower than that of ordinary concrete. The incorporation of graphene accelerates the hydration reaction of cement. Meanwhile, graphene nanoparticles effectively fill the spaces among pores and make the concrete denser than ordinary concrete. This slows down the carbonation reaction of concrete. However, when the temperature reaches $33^{\circ} \mathrm{C}$, there is little difference between the carbonation depth of the two kinds of concrete. When the temperature is higher than $33{ }^{\circ} \mathrm{C}$ (carbonation time is 21 days), Figure 7 shows that the carbonation depth of graphene concrete is deeper than that of ordinary concrete, which indicates that graphene will promote the carbonation reaction of concrete during this period, probably because graphene has excellent thermal conductivity. Moreover, the large specific surface area of GNP results in a larger contact area with concrete materials, which is conducive to the heat conduction of concrete and accelerates the carbonation reaction of graphene concrete.

\subsection{Variable Humidity}

Two groups of concrete specimens were subjected to a changing relative humidity scenario, ranging from $50 \%$ to $85 \%$, while the $\mathrm{CO}_{2}$ concentration and temperature were $6 \%$ and $25{ }^{\circ} \mathrm{C}$, respectively. The 28-day compressive strengths of GC0 and GC0.05 were 33.2 and $39.1 \mathrm{MPa}$, respectively.

\subsubsection{Scanning Electron Microscopy}

In this part, ordinary concrete and graphene concrete specimens without carbonation test and with $71 \%$ and $85 \%$ humidity exposure to carbonation experiment (carbonation time was 0, 21, and 35 days, respectively) were selected for SEM tests to study the micro morphology of two kinds of concrete before and after the humidity change. The SEM images of concrete at different humidity are shown in Figures 8 and 9. 


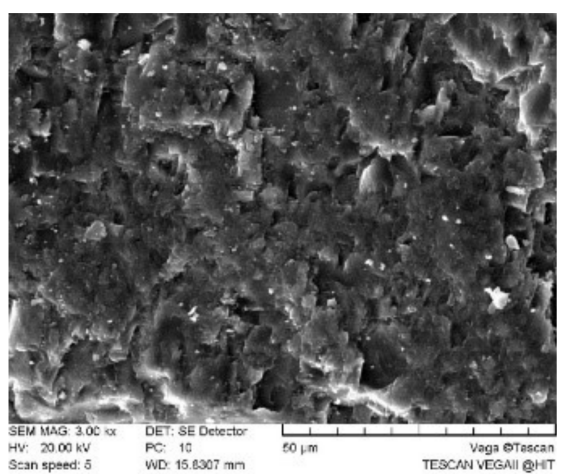

(a)

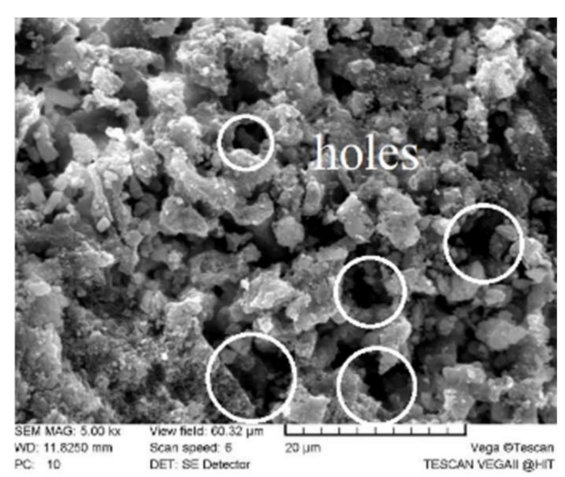

(b)

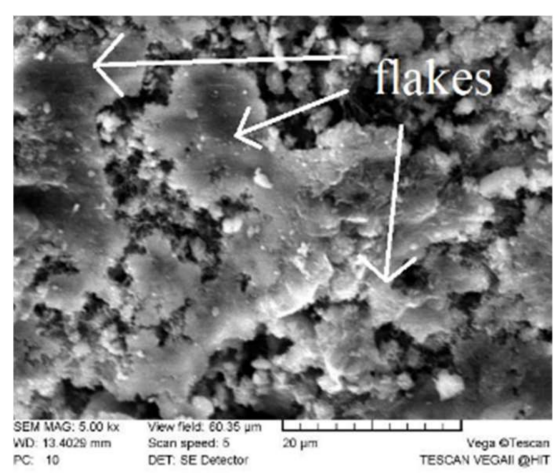

(c)

Figure 8. SEM images of the plain concrete in different corrosion humidity: (a) no corrosion, (b) humidity $71 \%$ (time 21 days), and (c) humidity $85 \%$ (time 35 days).

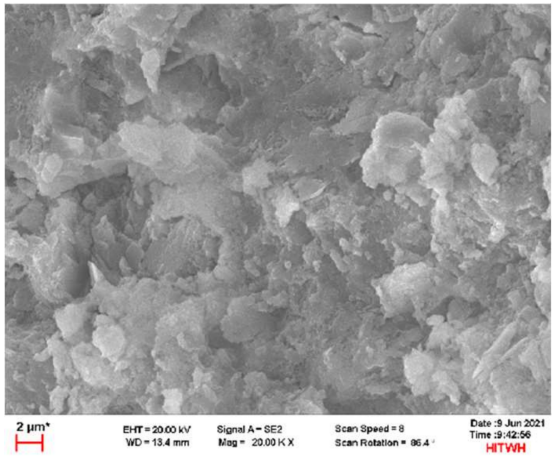

(a)

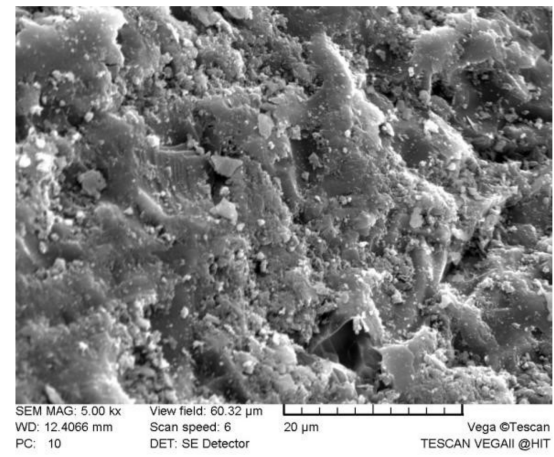

(b)

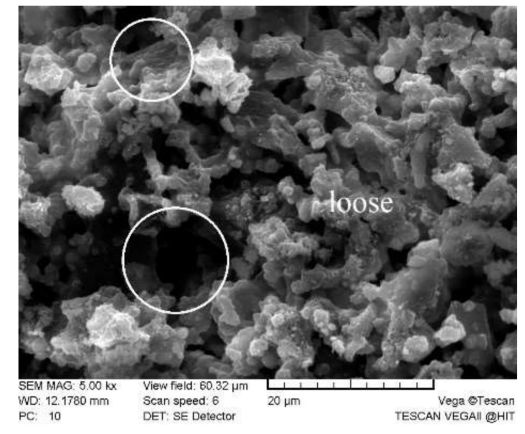

(c)

Figure 9. SEM images of the graphene concrete in different corrosion humidity: (a) no corrosion, (b) humidity $71 \%$ (time 21 days), and (c) humidity $85 \%$ (time 35 days).

Figure 8a shows that there are a lot of fibrous C-S-H gels in the inner structure of the no corrosion concrete. The gels are closely arranged, and there are few fine pores. The square plate $\mathrm{Ca}(\mathrm{OH})_{2}$ crystal and the needle rod ettringite Aft crystal overlap with each other, and the whole structure is relatively uniform. As shown in Figure $8 b$, for the ordinary concrete, after 21 days of carbonation (at $71 \%$ humidity), more spherical calcium carbonate crystals are generated, and square plate $\mathrm{Ca}(\mathrm{OH})_{2}$ crystals and intercalated cementitious C-S-H gel are observed. Compared with Figure 8a, there are many holes and some interconnections between them. With the extension of the carbonation time and the increase in humidity, Figure $8 \mathrm{c}$ shows that more spherical calcium carbonate crystals are filled inside the concrete, but the $\mathrm{CH}$ crystals are reduced and some of them are connected with each other to form flakes. We also observe that the number of calcium carbonate and $\mathrm{CH}$ crystals in Figure $8 \mathrm{~b}$ is obviously more than that in Figure 5b, which indicates that the influence of humidity on the carbonation of concrete may be greater than that of temperature under the condition of the same concentration of carbon dioxide and the same carbonation time (21 days).

Compared with Figure 9a, Figure 9b shows that there are a small amount of spherical calcium carbonate crystals and needle rod ettringite (Aft) crystals, and more six square plate $\mathrm{Ca}(\mathrm{OH})_{2}$ crystals and hydrated calcium silicate gels can be observed, and these gels accumulate with each other. This means that the carbonation reaction is slow, and the products of carbonation are less. Compared with Figure 8b, the graphene concrete after 21 days of carbonation (at $71 \%$ humidity) has more $\mathrm{Ca}(\mathrm{OH})_{2}$ crystals and little $\mathrm{CaCO}_{3}$ crystals, which indicates that the carbonation reaction of graphene concrete is slower than ordinary concrete in the same environment; that is, graphene delays the carbonation reaction. It can be seen in Figure $9 \mathrm{c}$ that there are still more square plate-shaped $\mathrm{Ca}(\mathrm{OH})_{2}$ crystals, the amount of spherical calcium carbonate in graphene concrete is significantly increased compared with 
that in Figure 9b, and the microstructure becomes loose and coral like, with large voids, which means that more hydration products participate in the carbonation reaction.

\subsubsection{Carbonation Depth}

The relationship between the carbonation depth of GC0 and GC0.05 with different humidity is shown in Figure 10.

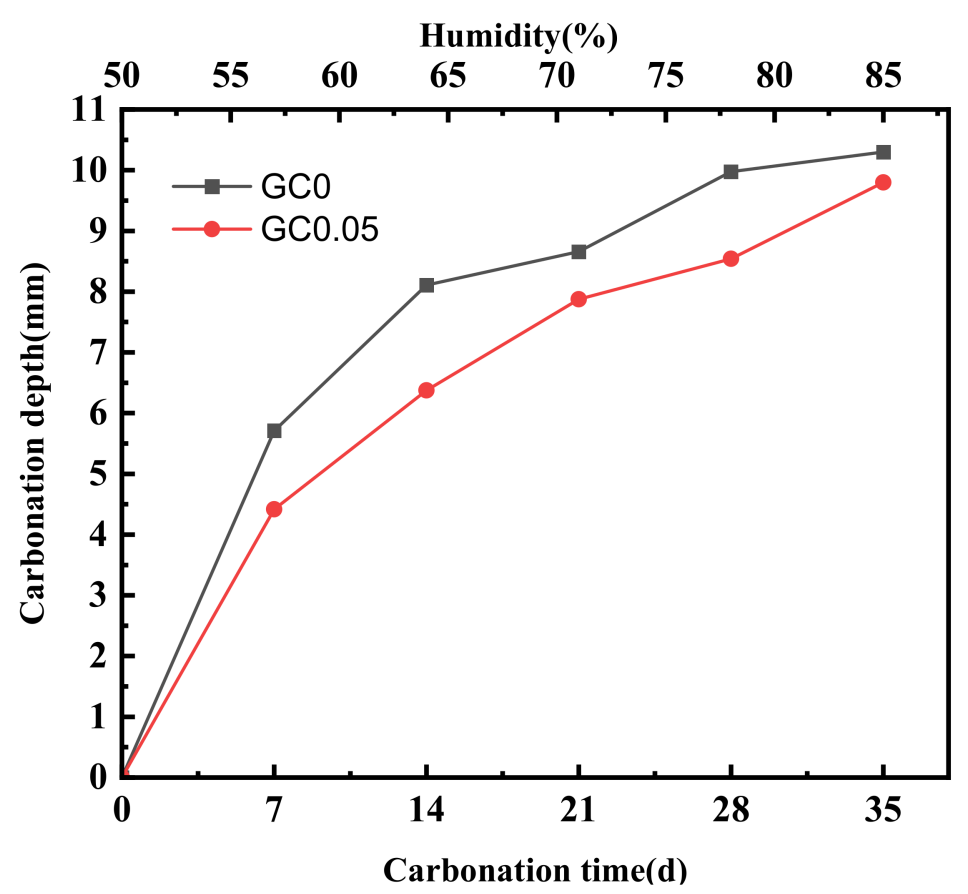

Figure 10. Relationship between concrete carbonation depth, time, and humidity.

It can be found that the carbonation depth of the two kinds of concrete is gradually increasing, but the carbonation depth of GC0.05 is generally $15 \%$ to $30 \%$ lower than that of GC0. These data indicate that the incorporation of GNP can slow down the carbonation process in these changing relative humidity scenarios. When the humidity is $78-85 \%$ (time is 28 to 35 days), the carbonation depth of graphene concrete and ordinary concrete increases slightly, which indicates that with the extension of time, the carbonation reaction of the two kinds of concrete almost stops when the relative humidity of the external climate is high. This may be because the pore water saturation of graphene concrete and ordinary concrete is relatively high within a certain period of time. At the same time, the carbonation reaction will produce new water and more water in the concrete, which will hinder the penetration speed of $\mathrm{CO}_{2}$ gas into the concrete and then prevent the chemical reaction in the process of carbonation.

\section{Conclusions}

This work investigated the influence of graphene on the carbonation depth of concrete under the simulated changing climate conditions. A set of experimental explorations were performed. Graphene concrete adopts the optimal dosage of 0.05\%wt. GC0 and GC0.05 specimens were prepared for accelerated carbonation experiments. The main conclusions were as follows.

(1) When the concentration of carbon dioxide changed from $6 \%$ to $10 \%$ (the temperature was $25{ }^{\circ} \mathrm{C}$ and the humidity was $65 \%$ ), the changes in the carbonation depth and microstructure of concrete with different corrosion degrees were revealed. The results show that the addition of graphene can delay the carbonation reaction of concrete.

(2) When the temperature changed from 25 to $45^{\circ} \mathrm{C}$ (the humidity was $65 \%$ and the $\mathrm{CO}_{2}$ concentration was $6 \%$ ), the test results show that in different temperature ranges, GNP 
has different effects on concrete. At $25-33^{\circ} \mathrm{C}$, the incorporation of GNP improves the carbonation resistance of concrete; however, above $33^{\circ} \mathrm{C}$, GNP concrete does not delay the carbonation of concrete. This means that graphene concrete may increase the carbonation rate of concrete in high-temperature areas. Additionally, the relationship between different grades graphene concrete with temperature with respect to the other parameters can be investigated in future work.

(3) When the humidity changed from $50 \%$ to $85 \%$ (the temperature was $25{ }^{\circ} \mathrm{C}$ and the concentration of $\mathrm{CO}_{2}$ was $6 \%$ ), the carbonation depth of graphene concrete was $15 \%$ lower than that of ordinary concrete.

(4) Under the condition of simulating climate change, it is considered that the influencing factors of carbonation of concrete are $\mathrm{CO}_{2}$ concentration, humidity, and temperature in order of magnitude.

This paper only discusses the influence of graphene on the carbonation depth of concrete under the condition of climate change, but in the actual service environment, concrete works under combined effects of some factors, such as freeze-thaw cycles and carbonation, acid rain, and carbonation, etc., which needs further research.

Author Contributions: Y.Z. wrote the manuscript, G.C. and H.W. designed the theoretical framework, Y.W., S.Z. and M.Y. performed the experiments. All authors have read and agreed to the published version of the manuscript.

Funding: This research was funded by Shandong Provincial Natural Science Foundation (Grant No. ZR2019MEE090 and ZR2020ME239).

Institutional Review Board Statement: Not applicable.

Informed Consent Statement: Not applicable.

Data Availability Statement: Not applicable.

Acknowledgments: We thank the Analysis and Testing Center of Harbin University of Technology (Weihai) for assistance with the SEM analysis.

Conflicts of Interest: The authors declare no conflict of interest.

\section{References}

1. Ekolu, S.O. Model for natural carbonation prediction (NCP): Practical application worldwide to real life functioning concrete structures. Eng. Struct. 2020, 224, 111126. [CrossRef]

2. Jiang, C.; Gu, X.; Huang, Q.; Zhang, W. Carbonation depth predictions in concrete bridges under changing climate conditions and increasing traffic loads. Cem. Concr. Compos. 2018, 93, 140-154. [CrossRef]

3. Mi, R.; Pan, G.; Liew, K.M. Predicting carbonation service life of reinforced concrete beams reflecting distribution of carbonation zones. Constr. Build. Mater. 2020, 255, 119367. [CrossRef]

4. Sun, B.; Xiao, R.-C.; Ruan, W.-D.; Wang, P.-B. Corrosion-induced cracking fragility of RC bridge with improved concrete carbonation and steel reinforcement corrosion models. Eng. Struct. 2020, 208, 110313. [CrossRef]

5. Benítez, P.; Rodrigues, F.; Talukdar, S.; Gavilán, S.; Varum, H.; Spacone, E. Analysis of correlation between real degradation data and a carbonation model for concrete structures. Cem. Concr. Compos. 2019, 95, 247-259. [CrossRef]

6. Ekolu, S.O. Implications of global $\mathrm{CO}_{2}$ emissions on natural carbonation and service lifespan of concrete infrastructures-Reliability analysis. Cem. Concr. Compos. 2020, 114, 103744. [CrossRef]

7. Jiang, C.; Huang, Q.; Gu, X.; Zhang, W. Experimental investigation on carbonation in fatigue-damaged concrete. Cem. Concr. Res. 2017, 99, 38-52. [CrossRef]

8. Jiang, C.; Huang, Q.-H.; Gu, X.-L.; Zhang, W.-P. Modeling the effects of fatigue damage on concrete carbonation. Constr. Build. Mater. 2018, 191, 942-962. [CrossRef]

9. Yoon, I.-S.; Çopuroğlu, O.; Park, K.-B. Effect of global climatic change on carbonation progress of concrete. Atmos. Environ. 2007, 41, 7274-7285. [CrossRef]

10. Pan, G.; Zhan, M.; Fu, M.; Wang, Y.; Lu, X. Effect of $\mathrm{CO}_{2}$ curing on demolition recycled fine aggregates enhanced by calcium hydroxide pre-soaking. Constr. Build. Mater. 2017, 154, 810-818. [CrossRef]

11. Working Group I to the Fifth Assessment Report of the Intergovernmental Panel on Climate Change. Summary for Policymakers. In Climate Change 2013: The Physical Science Basis; IPCC Intergovernmental Panel on Climate Change: Geneva, Switzerland, 2014.

12. WMO. Greenhouse Gas Bulletin: The State of Greenhouse Gases in the Atmosphere Based on Global Observations through 2016. 2017. Available online: https:/ /library.wmo.int/index.php?lvl=notice_display\&id=20041\#.YVq60n2-uUk. 
13. McMichael, A.J.; Woodruff, R.E.; Hales, S. Climate change and human health: Present and future risks. Lancet 2006, 367, 859-869. [CrossRef]

14. Stewart, M.G.; Wang, X.; Nguyen, M.N. Climate change impact and risks of concrete infrastructure deterioration. Eng. Struct. 2011, 33, 1326-1337. [CrossRef]

15. Stewart, M.G.; Wang, X.; Nguyen, M.N. Climate change adaptation for corrosion control of concrete infrastructure. Struct. Saf. 2012, 35, 29-39. [CrossRef]

16. Peng, L.; Stewart, M.G. Climate change and corrosion damage risks for reinforced concrete infrastructure in China. Struct. Infrastruct. Eng. 2014, 12, 499-516. [CrossRef]

17. Chen, G.; Lv, Y.; Zhang, Y.; Yang, M. Carbonation depth predictions in concrete structures under changing climate condition in China. Eng. Fail. Anal. 2021, 119, 104990. [CrossRef]

18. Fan, Y.; Zhang, S.; Wang, Q.; Shah, S.P. Effects of nano-kaolinite clay on the freeze-thaw resistance of concrete. Cem. Concr. Compos. 2015, 62, 1-12. [CrossRef]

19. Fan, Y.; Zhang, S.; Wang, Q.; Shah, S.P. The effects of nano-calcined kaolinite clay on cement mortar exposed to acid deposits. Constr. Build. Mater. 2016, 102, 486-495. [CrossRef]

20. Song, S.; Jiang, L.; Jiang, S.; Yan, X.; Xu, N. The mechanical properties and electrochemical behavior of cement paste containing nano-MgO at different curing temperature. Constr. Build. Mater. 2018, 164, 663-671. [CrossRef]

21. Liu, Y.; Chen, B.; Qin, Z. Effect of nano-silica on properties and microstructures of magnesium phosphate cement. Constr. Build. Mater. 2020, 264, 120728. [CrossRef]

22. Zheng, H.; Dai, J.-G.; Hou, L.; Meng, G.; Poon, C.S.; Li, W. Enhanced passivation of galvanized steel bars in nano-silica modified cement mortars. Cem. Concr. Compos. 2020, 111, 103626. [CrossRef]

23. Zhan, B.J.; Xuan, D.X.; Poon, C.S. The effect of nanoalumina on early hydration and mechanical properties of cement pastes. Constr. Build. Mater. 2019, 202, 169-176. [CrossRef]

24. Liu, J.; Li, Q.; Xu, S. Reinforcing Mechanism of Graphene and Graphene Oxide Sheets on Cement-Based Materials. J. Mater. Civil. Eng. 2019, 31, 04019014. [CrossRef]

25. Mohammed, A.; Sanjayan, J.G.; Duan, W.H.; Nazari, A. Graphene Oxide Impact on Hardened Cement Expressed in Enhanced Freeze-Thaw Resistance. J. Mater. Civil. Eng. 2016, 28, 04016072. [CrossRef]

26. Wang, B.; Zhao, R. Effect of graphene nano-sheets on the chloride penetration and microstructure of the cement based composite. Constr. Build. Mater. 2018, 161, 715-722. [CrossRef]

27. Pan, Z.; He, L.; Qiu, L.; Korayem, A.H.; Li, G.; Zhu, J.W.; Collins, F.; Li, D.; Duan, W.H.; Wang, M.C. Mechanical properties and microstructure of a graphene oxide-cement composite. Cem. Concr. Compos. 2015, 58, 140-147. [CrossRef]

28. Wang, Q.; Wang, J.; Lu, C.-X.; Liu, B.-W.; Zhang, K.; Li, C.-Z. Influence of graphene oxide additions on the microstructure and mechanical strength of cement. New Carbon Mater. 2015, 30, 349-356. [CrossRef]

29. Du, H.; Gao, H.J.; Pang, S.D. Improvement in concrete resistance against water and chloride ingress by adding graphene nanoplatelet. Cem. Concr. Res. 2016, 83, 114-123. [CrossRef]

30. Chen, G.; Yang, M.; Xu, L.; Zhang, Y.; Wang, Y. Graphene Nanoplatelets Impact on Concrete in Improving Freeze-Thaw Resistance. Appl. Sci. 2019, 9, 3582. [CrossRef]

31. People's Republic of China National Standard. In Standard for Test. Methods of Performance on Ordinary Fresh Concrete (GB/T50080 2016); China Architecture and Building Press: Beijing, China, 2016.

32. People's Republic of China National Standard. In Standard for Test. Methods of Long-Term Performance and Durability of Ordinary Concrete (GB/T 50082-2009); China Architecture and Building Press: Beijing, China, 2009.

33. Talukdar, S.; Banthia, N.; Grace, J.R. Carbonation in concrete infrastructure in the context of global climate change-Part 1: Experimental results and model development. Cem. Concr. Compos. 2012, 34, 924-930. [CrossRef]

34. Geng, G.L.Y.Y.O. The effect of climatic conditions on the carbonization rate of concrete. Concrete 2004, 11, 49-51.

35. People's Republic of China National Standard. In Standard for Test. Methods of Concrete Physical and Mechanical Properties (GB/T 50081-2019); China Architecture and Building Press: Beijing, China, 2002.

36. Cao, M.L.; Zhang, H.; Cong, Z. Effect of graphene on mechanical properties and microstructure of cement paste. J. Harbin. Inst. Technol. 2015, 47, 26-30. 